\title{
In-hospital complications and 1-year outcome of acute coronary syndrome in patients with hypertension: findings from the 2nd Gulf Registry of Acute Cardiac Events
}

\author{
W.M. Ali, ${ }^{1}$ K.F. Al Habib, ${ }^{2}$ A. Hersi, ${ }^{2}$ N. Asaad, ${ }^{1}$ K. Sulaiman, ${ }^{3}$ A. Al-Shiek-Ali ${ }^{4}$ and J. Al Suwaidi ${ }^{1}$
}

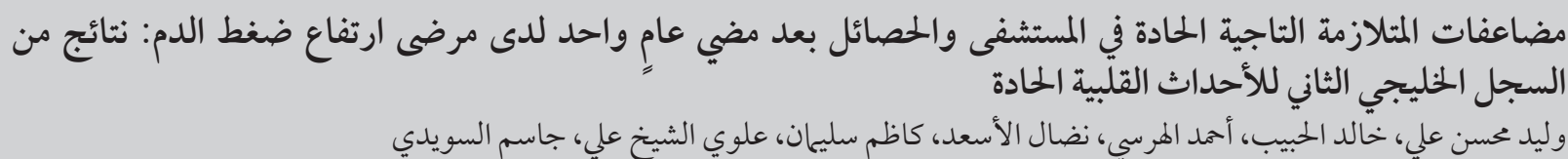

$$
\begin{aligned}
& \text { الخلاصـة: وقد استفاد الباحثون من المعطيات في السجل الخليجي الثاني للأحداث القلبية الحادة للعامين 2008-2009 لاستقصاء المضاعفات في }
\end{aligned}
$$

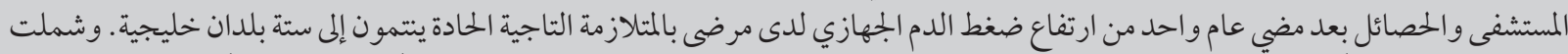

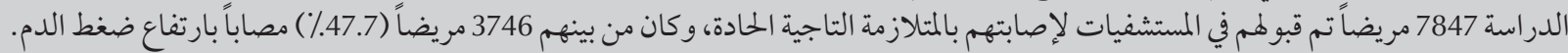

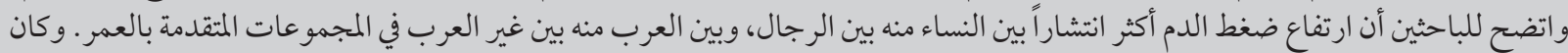

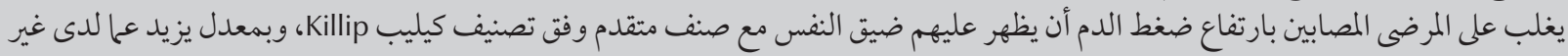

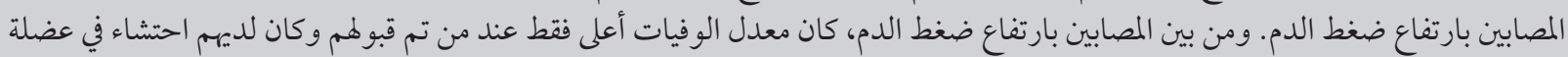

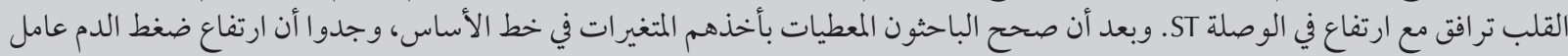

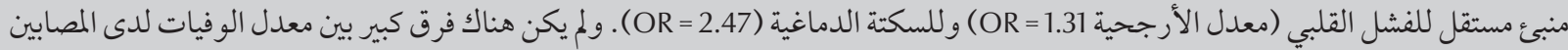

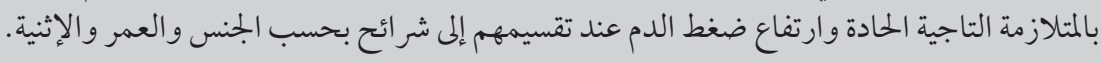

ABSTRACT Using data from the 2nd Gulf Registry of Acute Coronary Events (Gulf RACE-2) in 2008-09 we investigated the in-hospital complications and 1-year outcome of acute coronary syndrome (ACS) in patients with systemic hypertension from 6 Gulf countries. Of 7847 consecutive patients admitted with ACS, 3746 (47.7\%) had hypertension. Hypertension was more prevalent in women, in Arabs than non-Arabs and in older age groups. Patients with hypertension were more likely than those without hypertension to present with dyspnoea and advanced Killip class. Among hypertensive patients, the mortality rate was higher only among those admitted with ST-elevation myocardial infarction. After adjustment for baseline variables, hypertension was an independent predictive factor for heart failure $(O R=1.31)$ and stroke $(O R=2.47)$. There were no significant differences in mortality in hypertensive ACS patients when stratified by sex, age or ethnicity.

Complications hospitalières et issue à un an d'un syndrome coronarien aigu chez des malades hypertendus : résultats obtenus à partir du deuxième Registre des événements coronariens aigus du Golfe

RÉSUMÉ À partir de données du deuxième Registre des événements coronariens aigus du Golfe (Gulf RACE-2), pour la période 2008 - 2009, nous avons enquêté sur les complications à l'hôpital et sur l'issue à un an d'un syndrome coronarien aigu chez des patients atteints d'hypertension artérielle systémique dans six pays du Golfe. Sur 7847 patients admis consécutivement pour un syndrome coronarien aigu, 3746 souffraient d'hypertension (47,7 \%). L'hypertension était plus forterment prévalente chez les femmes, chez les patients arabes que chez les personnes d'un autre groupe ethnique et dans les tranches d'âge supérieur. Les patients hypertendus avaient une plus grande probabilité que les patients ayant une tension normale de souffrir de dyspnée et d'atteindre un stade élevé dans la classification de Killip. Chez les patients hypertendus, le taux de mortalité était plus élevé uniquement chez les patients admis pour un infarctus du myocarde avec sus-décalage du segment ST. Après ajustement des résultats en fonction des variables de référence, I'hypertension s'est révélé être un facteur prédictif indépendant de l'insuffisance cardiaque $(O R=1,31)$ et de l'accident vasculaire cérébral $(\mathrm{OR}=2,47)$. Aucune différence significative n'a été observée dans la mortalité des patients atteints d'un syndrome coronarien aigu après stratification par sexe, par âge, ou par groupe ethnique.

'Department of Cardiology and Cardiovascular Surgery, Hamad General Hospital and Weill Cornell Medical School, Doha, Qatar (Correspondence to J.Al Suwaidi:jalsuwaidi @hotmail.com).2King Fahad Cardiac Centre, King Khalid University Hospital College of Medicine, Riyadh, Saudi Arabia. ${ }^{3}$ Department of Cardiology, Royal Hospital, Muscat, Oman. ${ }^{4}$ Department of Cardiology, Sheikh Khalifa Medical City, Abu Dhabi, United Arab Emirates Received: 03/06/11; accepted: 26/07/11 


\section{Introduction}

Hypertension is widely acknowledged to increase the risk of premature cardiovascular disease, including stroke, coronary artery disease (CAD), heart failure and peripheral vascular disease $[1-3]$. In the INTERHEART study of patients from 52 countries, hypertension accounted for $18 \%$ of the population-attributable risk of a first myocardial infarction [2]. Furthermore, hypertension is the most common and most important risk factor for stroke and intracerebral haemorrhage and the incidence of these disease can be markedly reduced by effective antihypertension therapy $[4,5]$. The global prevalence of hypertension is high. It is estimated that $26 \%$ of the world adult population (972 million) had hypertension in the year 2000 [6]. In the United States, 58 to 65 million people with hypertension were reported in the National Health and Nutrition Examination Survey (NHANES) data from 1999-2000 [7]. The prevalence of hypertension was $28 \%$ and $44 \%$ in Canada and 6 European countries respectively [8].

We have recently reported a $49.4 \%$ prevalence of hypertension among patients with acute coronary syndrome (ACS) using data from the 1st Gulf Registry of Acute Coronary Events (Gulf RACE) [9]. Hypertension was not independently associated with increased risk of in-hospital mortality except in patients with ST-elevation myocardial infarction (STEMI). In the present study, using data from the 2nd GulfRACE registry (GulfRACE2 ), we evaluated the in-hospital and 1 -year outcomes of patients with ACS in relation to their hypertension status. We also evaluated the prevalence of hypertension and outcomes of these patients according to age, sex and ethnicity.

\section{Methods}

\section{Sample}

The data were collected from the Gulf RACE-2, which was a 9-month prospective, multicentre study of 7847 consecutive patients with ACS from 6 adjacent Gulf countries (Bahrain, Saudi Arabia, Qatar, Oman, United Arab Emirates and Yemen). Patients diagnosed with ACS, including unstable angina and non-ST- and ST-elevation myocardial infarction (NSTEMI and STEMI respectively), were recruited from 65 hospitals. An on-site cardiac catheterization laboratory was available in $43 \%$ of the hospitals and a coronary care unit onsite in $71 \%$ of hospitals. There were no exclusion criteria and thus all patients with ACS were enrolled.

Diagnosis of the different types of ACS and definitions of data variables were based on the American College of Cardiology clinical data standards [9]. The history of hypertension was obtained and recorded at the time of presentation. The study received ethical approval from the institutions' ethics committees in all participating countries.

\section{Data collection}

Details about the Gulf RACE methods have been published previously [10]. A case report form for each patient with suspected ACS was filled out on hospital admission by assigned physicians and/ or research assistants working in each hospital using standard definitions and was completed throughout the patient's hospital stay. All forms were verified by a cardiologist then sent online to the principal coordinating centre, where the forms were further checked for mistakes before submission for final analysis. To avoid double-counting of multiple admissions to the registry, the patients' national identification numbers and an assigned registry number were used. Thus, only the second ACS admission was included for each patient registered more than once.

Patients were divided into hypertensive and non-hypertensive groups. Systemic hypertension was defined in the current registry as: either history of hypertension diagnosed and treated with medication, diet and/or exercise; or blood pressure $>140 \mathrm{mmHg}$ systolic and/or diastolic pressure $>90 \mathrm{mmHg}$ on at least 2 occasions. Any history of hypertension was obtained and recorded at the time of presentation. For this study, patients were analysed according to the presence or absence of a diagnosis of hypertension.

\section{Statistical analysis}

Patients' characteristics were presented as proportions, mean and standard deviation (SD) as appropriate. Whenever possible, rates were used to describe patient populations. The frequencies of categorical variables in the 2 groups (hypertensive and non-hypertensive) were compared using the chi-squared test. Continuous variables were compared using the 2-tailed Student $t$-test. Variables influencing in-hospital mortality, cardiogenic shock and stroke were assessed with multiple logistic regressions after adjustment for confounders (i.e. age, sex, diabetes mellitus, hypertension, dyslipidaemia, smoking, thrombolytic therapy and khat use). Odds ratios (OR), 95\% confidence interval (CI) and $P$-values were reported for significant predictors. A $P$-value $<0.05$ was considered significant. All $P$-values were the results of 2-tailed tests. All data analyses were carried out using SPSS, version 14 .

\section{Results}

\section{Patients' characteristics}

Gulf RACE-2 enrolled 7847 patients with ACS from 6 Gulf countries, 3746 (47.7\%) of whom had hypertension. Patients with hypertension were 


\begin{tabular}{|c|c|c|c|c|c|}
\hline \multirow{2}{*}{$\begin{array}{l}\text { Variable } \\
\text { Demographic data }\end{array}$} & \multicolumn{2}{|c|}{$\begin{array}{l}\text { Hypertensive } \\
\qquad(n=3746)\end{array}$} & \multicolumn{2}{|c|}{$\begin{array}{l}\text { Normotensive } \\
\qquad(n=4101)\end{array}$} & $P$-value \\
\hline & & & & & \\
\hline Age [mean (SD)] (years) & 59.7 & $(11.7)$ & 54.3 & $(12.8)$ & $<0.001$ \\
\hline Male (No., \%) & 2239 & 59.8 & 3543 & 86.4 & $<0.001$ \\
\hline Arab ethnicity (No., \%) & 2868 & 76.6 & 2739 & 68.8 & $<0.001$ \\
\hline \multicolumn{6}{|l|}{ Clinical history } \\
\hline History of CAD (No., \%) & 1997 & 54.0 & 1229 & 30.0 & $<0.001$ \\
\hline History of heart failure (No., \%) & 382 & 10.0 & 140 & 3.0 & $<0.001$ \\
\hline Prior coronary revascularization (No., \%) & 708 & 19.0 & 275 & 6.7 & $<0.001$ \\
\hline Dyslipidaemia (No., \%) & 1847 & 49.0 & 742 & 18.0 & $<0.001$ \\
\hline Family history of CAD (No., \%) & 469 & 12.5 & 336 & 8.0 & 0.9 \\
\hline Diabetes mellitus (No., \%) & 2024 & 54.7 & 1089 & 26.9 & $<0.001$ \\
\hline Current smoking (No., \%) & 961 & 25.7 & 1839 & 44.8 & $<0.001$ \\
\hline History of renal failure (No., \%) & 277 & 7.4 & 39 & 1.0 & $<0.001$ \\
\hline History of stroke (No., \%) & 269 & 7.0 & 69 & 1.7 & $<0.001$ \\
\hline Prior aspirin use (No., \%) & 2133 & 58.5 & 1058 & 25.8 & $<0.001$ \\
\hline Prior $\beta$-blocker use (No., \%) & 1712 & 45.7 & 585 & 14.3 & $<0.001$ \\
\hline Prior ACE use (No., \%) & 1558 & 41.6 & 473 & 11.5 & $<0.001$ \\
\hline \multicolumn{6}{|l|}{ Clinical data at presentation } \\
\hline Presentation within 12 h of event (No., \%) & 332 & 53 & 619 & 60.9 & $<0.001$ \\
\hline Heart rate [mean (SD)] (beats/min) & 85 & $(20)$ & 84 & $(20)$ & 0.02 \\
\hline Systolic BP [mean (SD)] (mmHg) & 144 & $(31)$ & 128 & $(25)$ & $<0.001$ \\
\hline Diastolic BP [mean (SD)] (mmHg) & 84 & (19) & 78 & (16) & $<0.001$ \\
\hline BMI $[$ mean $(\mathrm{SD})]\left(\mathrm{kg} / \mathrm{m}^{2}\right)$ & 27.7 & $(6.0)$ & 26.0 & (4.8) & $<0.001$ \\
\hline Ischemic chest pain (No., \%) & 2993 & 74.2 & 3489 & 84.4 & $<0.001$ \\
\hline Dyspnoea (No., \%) & 574 & 14.2 & 226 & 5.5 & $<0.001$ \\
\hline Killip class > I (No., \%) & 1052 & 28.0 & 753 & 18.4 & $<0.001$ \\
\hline GRACE score (No., \%) & & & & & $<0.001$ \\
\hline Low & 2340 & 63.0 & 2963 & 73.6 & \\
\hline Intermediate & 1048 & 28.0 & 820 & 20.4 & \\
\hline High & 322 & 8.7 & 245 & 6.0 & \\
\hline \multicolumn{6}{|l|}{ LV dysfunction (No., \%) } \\
\hline All cases & 2124 & 73.0 & 2307 & 74.0 & 0.3 \\
\hline Severe cases & 318 & 11.0 & 237 & 7.7 & $<0.001$ \\
\hline Coronary angiography (No., \%) & 1303 & 34.8 & 1254 & 30.6 & $<0.001$ \\
\hline Left main stem CAD & 87 & 6.7 & 58 & 4.6 & 0.02 \\
\hline Single-vessel CAD & 324 & 24.8 & 432 & 34.0 & $<0.001$ \\
\hline Two-vessel CAD & 297 & 22.7 & 322 & 25.7 & 0.8 \\
\hline Three-vessel CAD & 474 & 36.0 & 293 & 23.0 & $<0.001$ \\
\hline \multicolumn{6}{|l|}{ Laboratory findings [mean (SD)] } \\
\hline First blood sugar (mg/dL) & 11 & (5.8) & 9.7 & $(5.0)$ & $<0.001$ \\
\hline Fasting blood sugar (mg/dL) & 7.5 & (3.0) & 7.0 & (3.0) & $<0.001$ \\
\hline Peak CK-MB (ng/mL) & 74 & (127) & 122 & (177) & $<0.001$ \\
\hline First creatinine $(\mu \mathrm{mol} / \mathrm{L})$ & 111 & $(91)$ & 94 & (59) & $<0.001$ \\
\hline Total cholesterol (mg/dL) & 4.7 & (1.8) & 4.9 & (1.4) & $<0.001$ \\
\hline HDL cholesterol (mg/dL) & 1.0 & $(0.5)$ & 1.0 & $(0.5)$ & 0.5 \\
\hline LDL cholesterol (mg/dL) & 3.0 & (1.5) & 3.2 & (1.1) & $<0.001$ \\
\hline Fasting TG (mg/dL) & 1.8 & (1.1) & 1.7 & (1.1) & 0.054 \\
\hline First haemoglobin (g/L) & 13 & (2) & 14 & (2) & $<0.001$ \\
\hline
\end{tabular}

$S D=$ standard deviation; $C A D=$ coronary artery disease; $A C E=$ angiotensin-converting enzyme; $L V=$ left ventricular; $B P=$ blood pressure; $B M I=$ body mass index; $G R A C E$ = global registry of acute coronary events; $C K-M B=$ creatine kinase $M B$-fraction; $H D L=$ high-density lipoprotein; $L D L=$ low-density lipoprotein; $T G=$ triglycerides. 
significantly older and significantly more likely to be male than those without hypertension (Table 1). The clinical history showed that patients with hypertension were significantly more likely to have comorbidities, including higher rates of diabetes, dyslipidaemia, prior history of CAD, prior congestive heart failure, chronic renal insufficiency and stroke. However, they were less likely to be current smokers (Table 1).

On presentation to hospital, hypertensive patients with ACS had higher Killip class, body mass index (BMI), heart rate and systolic and diastolic blood pressure. Patients with hypertension were more likely to present with dyspnoea and to seek medical advice early (within 12 hours of the event) compared with non-hypertensive patients (Table 1).

Baseline serum creatinine, fasting blood sugar and first blood sugar levels were higher in patients with hypertension, whereas fasting serum triglycerides, low-density lipoprotein cholesterol and peak creatine kinase MB-fraction were higher in non-hypertensive patients.

In hypertensive patients with ACS, NSTEMI was the most frequent diagnosis (36.7\%), followed by STEMI (33.0\%) and unstable angina (30.0\%). Among non-hypertensive patients, $56.6 \%$ had STEMI, followed by NSTEMI (24.0\%) and unstable angina (19.0\%) (Table 2). Overall coronary angiography was performed in $38.4 \%$ of hypertension patients and $30.6 \%$ ofnonhypertensive patients. Hypertensive patients were more likely to have 3-vessel CAD and left main stem $C A D$, while non-hypertensive patients more commonly had 2- and single-vessel CAD (Table 1).

\section{In-hospital and discharge treatment}

On admission, hypertensive patients were more likely to receive angiotensin-converting enzyme inhibitors, angiotensin-receptor blockers, calciumchannel blockers and beta-blockers, but less likely to receive thrombolytics, unfractionated heparin and clopidogrel when compared with non-hypertensive patients. At discharge, hypertensive patients were more likely to be prescribed calcium-channel blockers, angiotensinreceptor blockers and beta-blockers and less likely to receive clopidogrel,

\begin{tabular}{|c|c|c|c|c|c|}
\hline \multirow[t]{2}{*}{ Variable } & \multicolumn{2}{|c|}{ Hypertensive } & \multicolumn{2}{|c|}{ Normotensive } & \multirow[t]{2}{*}{$P$-value } \\
\hline & No. & $\%$ & No. & $\%$ & \\
\hline \multicolumn{6}{|l|}{ Medication at admission } \\
\hline Thrombolysis & 540 & 46.9 & 1107 & 52.6 & 0.002 \\
\hline Aspirin & 3673 & 98.0 & 4046 & 98.7 & $<0.03$ \\
\hline Clopidogrel & 2802 & 74.8 & 3171 & 77.3 & 0.009 \\
\hline Heparin & 1415 & 37.9 & 1824 & 44.5 & $<0.001$ \\
\hline Heparin (LMW) & 1514 & 40.6 & 1434 & 35.0 & $<0.001$ \\
\hline Glycoprotein IIb/IIla inhibitor & 315 & 8.0 & 293 & 7.0 & 0.03 \\
\hline$\beta$-blocker & 2878 & 76.8 & 2959 & 72.0 & $<0.001$ \\
\hline ACE inhibitor & 2798 & 72.0 & 2848 & 69.4 & 0.01 \\
\hline Angiotensin receptor blocker & 331 & 8.8 & 63 & 1.5 & $<0.001$ \\
\hline Primary percutaneous coronary intervention & 562 & 22.0 & 574 & 20.0 & 0.1 \\
\hline Calcium-channel blocker & 454 & 12.0 & 116 & 2.8 & $<0.001$ \\
\hline \multicolumn{6}{|l|}{ Medication at discharge } \\
\hline Aspirin & 3464 & 95.4 & 3819 & 95.5 & 0.8 \\
\hline Clopidogrel & 2463 & 66.0 & 2845 & 69.5 & 0.01 \\
\hline Statin & 3383 & 90.7 & 3764 & 91.9 & 0.05 \\
\hline$\beta$-blocker & 3019 & 80.9 & 3188 & 77.9 & 0.001 \\
\hline ACE inhibitor & 2633 & 70.6 & 2948 & 72.0 & 0.2 \\
\hline Angiotensin receptor blocker & 408 & 10.9 & 128 & 3.0 & $<0.001$ \\
\hline Calcium-channel blocker & 488 & 13.0 & 123 & 3.0 & $<0.001$ \\
\hline \multicolumn{6}{|l|}{ Diagnosis at discharge } \\
\hline STEMI & 1246 & 33.0 & 2326 & 56.6 & $<0.001$ \\
\hline NSTEMI & 1374 & 36.7 & 993 & 24.0 & \\
\hline Unstable angina & 1128 & 30.0 & 789 & 19.0 & \\
\hline
\end{tabular}

ACE = angiotensin-converting enzyme; $L M W=$ low molecular weight $;$ STEMI = ST-elevation myocardial infarction; NSTEMI = non-ST elevation myocardial infarction. 
whereas prescription of aspirin, statin and angiotensin-converting enzyme inhibitors were comparable between the 2 groups (Table 2).

\section{Outcomes}

Compared with normotensive patients, hypertensive patients had significantly higher rates of in-hospital heart failure, recurrent myocardial ischaemia, atrial fibrillation and stroke (Table 3). Stroke was predominantly ischaemic in nature. Overall in-hospital, 1-month and 1 -year mortality rates were not statistically significant different between the 2 groups. However, hypertensive patients presenting with STEMI had higher rate of in-hospital mortality in addition to higher risk of heart failure, recurrent ischaemia, re-infarction and stroke when compared with non-hypertensive patients with STEMI. Among NSTEMI patients, however, hypertensive patients had a higher risk of heart failure only, while in patients with unstable angina, hypertension was associated with increased risk of heart failure and stroke when compared with non-hypertensive patients (Table 3). Bleeding complications were comparable between the 2 groups.

\section{Multivariate analysis}

Age, female sex, hypertension, diabetes mellitus, BMI, smoking and being on thrombolytic drugs were adjusted as confounders in a multivariate analysis for predictors of in-hospital heart failure and stroke in patients with ACS. Hypertension, age, smoking, diabetes mellitus and BMI were independent risk factors for in-hospital heart failure (Table 4). Only hypertension was a significant risk factor for stroke, $(\mathrm{OR}=2.47,95 \% \mathrm{CI}$ : 1.11-5.47, $P=0.02)$ (Table 4).

\section{Hypertension: prevalence and outcome by sex, age and ethnicity}

Hypertension was more prevalent among women with ACS (66.6\%) than among men $(38.7 \%)(P<0.001)$. In the

\begin{tabular}{|c|c|c|c|c|c|}
\hline \multirow[t]{2}{*}{ Variable } & \multicolumn{2}{|c|}{ Hypertensive } & \multicolumn{2}{|c|}{ Normotensive } & \multirow[t]{2}{*}{$P$-value } \\
\hline & No. & $\%$ & No. & $\%$ & \\
\hline All patients & \multicolumn{2}{|c|}{$(n=4036)$} & \multicolumn{2}{|c|}{$(n=4129)$} & \\
\hline In-hospital death & 168 & 4.5 & 185 & 4.5 & 1.0 \\
\hline 1-month death & 266 & 8.0 & 297 & 8.2 & 0.7 \\
\hline 1-year death & 386 & 13.3 & 374 & 11.8 & 0.08 \\
\hline Heart failure & 601 & 16.0 & 425 & 10.3 & $<0.001$ \\
\hline Recurrent ischaemia & 613 & 16.4 & 601 & 14.7 & 0.04 \\
\hline Re-infarction & 77 & 2.1 & 91 & 2.2 & 0.6 \\
\hline Cardiogenic shock & 192 & 5.1 & 256 & 6.2 & 0.2 \\
\hline Major bleeding & 24 & 0.6 & 22 & 0.5 & 0.5 \\
\hline Stroke & 35 & 0.9 & 18 & 0.4 & 0.007 \\
\hline Haemorrhagic & \multicolumn{2}{|l|}{ (9) } & \multicolumn{2}{|c|}{ (7) } & \\
\hline Thrombotic & \multicolumn{2}{|l|}{ (20) } & \multicolumn{2}{|c|}{ (9) } & \\
\hline Unknown & \multicolumn{2}{|l|}{ (6) } & \multicolumn{2}{|c|}{ (2) } & \\
\hline On ventilation & 191 & 5.1 & 171 & 4.2 & 0.05 \\
\hline $\mathrm{VF} / \mathrm{VT}$ & 142 & 3.8 & 186 & 4.6 & 0.06 \\
\hline Atrial fibrillation & 66 & 1.8 & 38 & 0.9 & 0.001 \\
\hline STEMI & \multicolumn{2}{|c|}{$(n=1244)$} & \multicolumn{2}{|c|}{$(n=2319)$} & \\
\hline In-hospital death & 105 & 8.4 & 141 & 6.1 & 0.008 \\
\hline Heart failure & 229 & 18.4 & 275 & 11.8 & $<0.001$ \\
\hline Recurrent ischemia & 278 & 22.3 & 376 & 16.2 & $<0.001$ \\
\hline Re-infarction & 55 & 4.4 & 71 & 3.1 & 0.03 \\
\hline Cardiogenic shock & 118 & 9.5 & 196 & 8.5 & 0.2 \\
\hline Stroke & 21 & 1.7 & 16 & 0.7 & 0.005 \\
\hline On ventilation & 97 & 7.8 & 119 & 5.1 & 0.001 \\
\hline $\mathrm{VF} / \mathrm{VT}$ & 69 & 5.7 & 109 & 4.8 & 0.2 \\
\hline NSTEMI & \multicolumn{2}{|c|}{$(n=1374)$} & \multicolumn{2}{|c|}{$(n=993)$} & \\
\hline In-hospital death & 56 & 4.1 & 39 & 3.9 & 0.8 \\
\hline Heart failure & 267 & 19.4 & 112 & 11.3 & $<0.001$ \\
\hline Recurrent ischemia & 193 & 14.0 & 135 & 13.6 & 0.7 \\
\hline Re-infarction & 19 & 1.4 & 19 & 1.9 & 0.3 \\
\hline Cardiogenic shock & 68 & 5.0 & 50 & 5.1 & 0.9 \\
\hline Stroke & 8 & 0.6 & 2 & 0.2 & 0.1 \\
\hline On ventilation & 78 & 5.7 & 45 & 4.5 & 0.2 \\
\hline $\mathrm{VF} / \mathrm{VT}$ & 21 & 1.5 & 16 & 1.6 & 0.8 \\
\hline Unstable angina & \multicolumn{2}{|c|}{$(n=1128)$} & \multicolumn{2}{|c|}{$(n=789)$} & \\
\hline In-hospital death & 7 & 0.6 & 5 & 0.6 & 0.9 \\
\hline Heart failure & 105 & 9.3 & 38 & 4.8 & $<0.001$ \\
\hline Recurrent ischemia & 142 & 12.6 & 90 & 11.4 & 0.4 \\
\hline Re-infarction & 3 & 0.3 & 1 & 0.1 & 0.5 \\
\hline Cardiogenic shock & 6 & 0.5 & 10 & 1.3 & 0.08 \\
\hline Stroke & 6 & 0.5 & 0 & 0.0 & 0.04 \\
\hline On ventilation & 16 & 1.4 & 7 & 0.9 & 0.2 \\
\hline $\mathrm{VF} / \mathrm{VT}$ & 3 & 0.3 & 5 & 0.6 & 0.2 \\
\hline
\end{tabular}

STEMI = ST-elevation myocardial infarction $;$ NSTEMI = non-ST elevation myocardial infarction $; \mathrm{VF}=$ ventricular fibrillation, $V T=$ ventricular tachycardia . 


\begin{tabular}{|c|c|c|c|c|}
\hline \multirow[t]{2}{*}{ Variable } & \multicolumn{2}{|c|}{ In-hospital heart failure } & \multicolumn{2}{|c|}{ In-hospital stroke } \\
\hline & OR $(95 \% \mathrm{CI})$ & $P$-value & OR $(95 \% \mathrm{Cl})$ & $P$-value \\
\hline Age & $1.03(1.02-1.04)$ & $<0.001$ & $1.02(0.99-1.05)$ & 0.2 \\
\hline Sex & $1.31(0.97-1.76)$ & 0.08 & $0.51(0.14-1.85)$ & 0.3 \\
\hline Hypertension & $1.31(1.05-1.65)$ & 0.02 & $2.47(1.11-5.47)$ & 0.02 \\
\hline Dyslipidaemia & $0.94(0.73-1.22)$ & 0.7 & $0.92(0.39-1.07)$ & 0.9 \\
\hline Diabetes mellitus & $1.54(1.22-1.94)$ & $<0.001$ & $1.42(0.64-3.13)$ & 0.3 \\
\hline Smoking & $1.35(1.05-1.72)$ & 0.01 & $1.65(0.68-3.98)$ & 0.3 \\
\hline Thrombolytic therapy & $0.58(0.46-0.73)$ & $<0.001$ & $0.59(0.27-1.30)$ & 0.2 \\
\hline BMI & $1.03(1.01-1.05)$ & 0.001 & $1.00(0.93-2.17)$ & 1.0 \\
\hline
\end{tabular}

$O R=$ odds ratio $; C l=$ confidence interval; $B M I=$ body mass index.

spectrum of ACS, women with or without hypertension had significantly higher in-hospital mortality (i.e. any death recorded during admission from time of arrival until discharge) and 1-month and 1-year mortality rates compared with men with or without hypertension (Table 5). The differences in mortality between women and men among hypertensive patients were no longer statistically significant after adjustment for age, diabetes mellitus, renal failure, BMI, smoking and hyperlipidaemia.

The prevalence of hypertension increased steadily with age, from $21.6 \%$ at age $<40$ years to $59.0 \%$ at $>70$ years. Mortality rates rose consistently with age among hypertensive and nonhypertensive patients with ACS, both in-hospital and during the follow-up period. When adjusted for sex and comorbidities, age was an independent predictor for in-hospital mortality in hypertensive $(\mathrm{OR}=1.04,95 \% \mathrm{CI}$ : 1.03-1.06, $P<0.001)$ and non-hypertensive patients $(\mathrm{OR}=1.06,95 \% \mathrm{CI}$ : $1.05-1.07, P<0.001)$.

Hypertension was more prevalent in Middle-Eastern Arab ethnicity when compared to non-Arabs (51.2\% versus $39.2 \%, P<0.001)$ and more prevalent in female Arabs (66.8\% versus 61.8\%, $P<$ 0.001). In-hospital, 1-month and 1-year mortality were higher in Arab hypertensive and non-hypertensive patients when compared with non-Arab ethnicity patients. In multivariate analysis, after adjustment for age, sex and comorbidities, Arab ethnicity was an independent predictor of in-hospital mortality (OR $=1.75,95 \%$ CI: $1.20-2.56, P=0.004$ ) but hypertension was not a predictor of in-hospital mortality (OR $=0.84,95 \%$ CI: $0.65-1.10, P=0.21)$.

\section{Discussion}

The data from the Gulf RACE-2 survey provides an insight into the prevalence and impact of hypertension in a broad Middle East population presenting with ACS. In Gulf RACE-1 we reported a high prevalence of hypertension in a Middle Eastern population presenting with ACS [9]. Hypertensive patients had a higher risk of heart failure than non-hypertensive patients. The mortality rate was also higher but only in hypertensive patients presenting with STEMI. The current study extends these observations using data from Gulf RACE-2, where the prevalence of hypertension was comparable to that reported from the first registry. Furthermore, the in-hospital mortality rate was comparable between the 2 groups. We also report for the first time that this comparable mortality rats extends up to 1 year follow-up with a trend of increased mortality among hypertensive patients. Patients with hypertension had a higher risk of heart failure complications regardless of the ACS subtype. Hypertension patients also had higher risk of recurrent myocardial infarction and the development of atrial fibrillation. We also report for the first time that among hypertensive MiddleEastern patients presenting with ACS hypertension was the only independent risk factor for stroke, which was primarily ischaemic in nature. Moreover, stroke risk appeared to be most prominent among STEMI patients.

The literature on the effect of hypertension on short- and long-term mortality is conflicting; many studies have claimed a deleterious effect of hypertension in ACS with an increasing risk of death [11-13] while others, including the current study and Gulf RACE-1, failed to show this $[6-9,11-19]$. Other investigators reported better outcomes in hypertensive patients presenting with ACS $[20,21]$. These conflicting results might be due to the complex impact of hypertension on ACS and the differences in patients' baseline characteristics such as age, sex and ethnicity as well as therapy among these various studies. Hypertension is well known to be associated with other morbidities, such as diabetes mellitus, dyslipidaemia, obesity and previous $\mathrm{CAD}$, that might collectively contribute to a deterioration in prognosis [13,20,22]. Moreover, left ventricular hypertrophy, heart failure and arrhythmia are known to be induced by hypertension $[13,20,22]$. However, some characteristics of hypertensive patients might attenuate the 


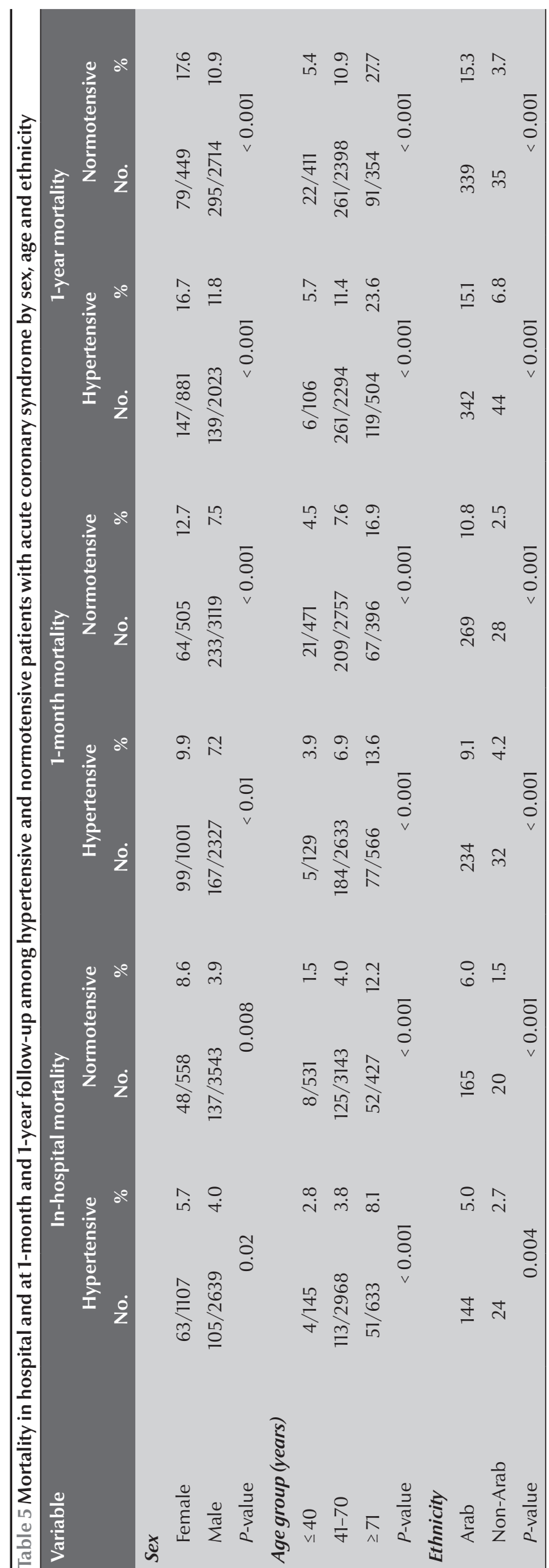

adverse factors in ACS, including smaller infarction sizes [23], better coronary artery perfusion in the presence of higher diastolic pressure, a well-developed collateral circulation in the setting of greater severity of coronary atherosclerosis and previous treatment with cardioprotective drugs [20]. This hypothesis of a balance between exacerbating and attenuating factors was clearly evident in Gulf RACE-2. Hypertensive patients were older, more often female and were more likely to have diabetes, dyslipidaemia, higher BMI and prior CAD. On the other hand, hypertensive patients were more likely to be on aspirin and beta-blockers prior to admission. Hypertensive patients also were more likely to receive recommended medications at admission including beta-blockers, angiotensin converting enzyme inhibitors, angiotensin II receptor blockers. NSTEMI was the predominant presentation in hypertensive patients and peak creatine kinase MB-fraction was lower, which supports the smaller infarction size, while in non-hypertension, STEMI occurred in almost half of patients.

The higher mortality rate of hypertensive patients with STEMI in our study is supported by many similar studies including our previous study in Gulf RACE-1 $[9,23]$. It seems that the deleterious effect of hypertension became more evident when the infarction size was large, resulting in higher recurrent ischaemia, heart failure and stroke, which in turn led in a higher risk of death.

Several factors may explain the higher risk of heart failure among hypertensive patients presenting with ACS. Diastolic dysfunction, due to hypertrophic and interstitial changes in chronic hypertension, ventricular remodelling and greater activation of neurohormonal systems (both in the early post-infarction period and several months later) [24], plus the higher incidence of diabetes mellitus in hypertensive patients, each independently and collectively enhance the risk of heart failure [25]. Nevertheless, heart failure is a major predictor of mortality in ACS [26] and the higher mortality in our study was limited to hypertensive patients with STEMI only. Although severe left ventricular dysfunction (systolic dysfunction) was higher among hypertensive patients compared with non-hypertensive patients in our study group, the overall prevalence of left ventricular dysfunction was comparable between the 2 groups, suggesting that a significant proportion of heart failure in hypertension may be attributed to diastolic dysfunction.

We found a higher incidence of stroke in hypertensive patients with ACS, which is unsurprising given that hypertension and acute myocardial infarction are independently associated with higher risk of stroke 


\begin{tabular}{|c|c|c|}
\hline \multicolumn{3}{|c|}{$\begin{array}{l}\text { Table } 6 \text { Mortality among hypertensive and normotensive patients with acute } \\
\text { coronary syndrome, unadjusted and adjusted to age and comorbidities by sex, } \\
\text { age and ethnicity }\end{array}$} \\
\hline \multirow[t]{2}{*}{ Variable } & \multicolumn{2}{|c|}{ OR $(95 \% \mathrm{CI})$} \\
\hline & Unadjusted & Adjusted \\
\hline \multicolumn{3}{|l|}{ Sex } \\
\hline In-hospital mortality & $1.78(1.42-2.23)$ & $1.80(1.42-2.85)$ \\
\hline 1-month mortality & $1.54(1.27-1.86)$ & $1.57(1.30-1.91)$ \\
\hline 1-year mortality & $1.63(1.38-1.93)$ & $1.59(1.34-1.89)$ \\
\hline \multicolumn{3}{|l|}{ Age } \\
\hline In-hospital mortality & $1.05(1.04-1.06)$ & $1.05(1.04-1.06)$ \\
\hline 1-month mortality & $1.04(1.03-1.05)$ & $1.05(1.03-1.05)$ \\
\hline 1-year mortality & $1.05(1.04-1.06)$ & $1.05(1.04-1.06)$ \\
\hline \multicolumn{3}{|l|}{ Ethnicity } \\
\hline In-hospital mortality & $2.92(2.13-4.00$ & $2.94(2.13-4.05)$ \\
\hline 1-month mortality & $3.38(2.58-4.41)$ & $3.42(2.61-4.51)$ \\
\hline 1-year mortality & $3.41(2.69-4.33)$ & $3.40(2.67-4.32)$ \\
\hline
\end{tabular}

$O R=$ odds ratio $; C l=$ confidence interval .

[27]. Ischaemic stroke was the main type in our registry, which means that atherosclerosis or embolic events are the likely causes, not thrombolytic therapy. Additionally we observed a higher prevalence of atrial fibrillation among hypertensive patients, which may be related to left atrial enlargement and the poor left ventricular function due to heart failure, both of which can make the heart the source of embolic stroke in hypertension patients with ACS. These findings emphasize the need for awareness of the risk of stroke by physicians treating hypertension in ACS patients.

Finally, the prevalence of hypertension in women presenting with ACS was higher than in men. The high prevalence of hypertension among
Middle Eastern women was also reported in Gulf RACE-1 (70\% versus $43 \%)$ [28]. Furthermore, the overall mortality rate was higher among women compared with men. This may be attributed to multiple factors including late and atypical presentations, less medication prescribed and a higher incidence of heart failure in women than men, as was reported by other investigators [29].

Some limitations of the study can be noted. Our data were collected from an observational study and the fundamental limitations of observational studies cannot be eliminated because of their non-randomized nature and unmeasured confounding factors. However, well-designed observational studies provide valid results and do not systematically overestimate the results compared with the results of randomized controlled trials. Finally, although long-term follow-up was reported, this was limited to mortality rates only and data about compliance with medical therapy in addition to the risk of other cardiovascular complications including recurrent myocardial ischaemia, infarction and heart failure were lacking.

\section{Conclusions}

Hypertension is highly prevalent among Middle-Eastern patients presenting with ACS particularly in women, older age groups and among Middle-Eastern Arab ethnicity. Hypertension was independently associated with increased risk of heart failure and stroke. In cases of STEMI, hypertension was associated with a higher risk of in-hospital mortality and stroke.

\section{Acknowledgements}

Gulf RACE is a Gulf Heart Association (GHA) project and was financially supported by the GHA, Sanofi Aventis, and the College of Medicine Research Center at King Khalid University Hospital, King Saud University, Riyadh, Saudi Arabia. The sponsors had no role in study design, data collection, data analysis, writing of the report, or submission of the manuscript.

\section{References}

1. Psaty BM et al. Association between blood pressure level and the risk of myocardial infarction, stroke, and total mortality: the cardiovascular health study. Archives of Internal Medicine, 2001, 161:1183-1192.

2. Yusuf $\mathrm{S}$ et al., INTERHEART Study Investigators. Effect of potentially modifiable risk factors associated with myocardial infarction in 52 countries (the INTERHEART study): case-control study. Lancet, 2004, 364:937-952.

3. Sesso HD et al. Systolic and diastolic blood pressure, pulse pressure, and mean arterial pressure as predictors of cardiovascular disease risk in Men. Hypertension, 2000, 36:801-807.
4. Staessen JA et al., The Systolic Hypertension in Europe (Syst-Eur) Trial Investigators. Randomised double-blind comparison of placebo and active treatment for older patients with isolated systolic hypertension. Lancet, 1997, 350:757-764.

5. Thrift AG et al.; Melbourne Risk Factor Study (MERFS) Group. Risk factors for cerebral hemorrhage in the era of well-controlled hypertension. Stroke, 1996, 27:2020-2025.

6. Kearney PM et al. Global burden of hypertension: analysis of worldwide data. Lancet, 2005, 365:217-223.

7. Fields LE et al. The burden of adult hypertension in the United States 1999 to 2000: a rising tide. Hypertension, 2004, 44:398-404. 
8. Wolf-Maier K et al. Hypertension prevalence and blood pressure levels in 6 European countries, Canada, and the United States. Journal of the American Medical Association, 2003, 289:2363-2369.

9. Ali WM et al. The prevalence and outcome of hypertension in patients with acute coronary syndrome in six Middle-Eastern countries. Blood pressure, 2010, 20(1):20-26.

10. Ali WM et al. Acute coronary syndrome and khat "herbal amphetamine" use: an observational report. Circulation, 2011, 124:2681-2689.

11. Kang DG et al., Korea Acute Myocardial Infarction Registry Investigators. Clinical effects of hypertension on the mortality of patients with acute myocardial infarction. Journal of Korean Medical Science, 2009, 24:800-806.

12. Dumaine $\mathrm{R}$ et al. Thrombolysis in Myocardial Infarction (TIMI) Study Group. Association of a history of systemic hypertension with mortality, thrombotic, and bleeding complications following non-ST-segment elevation acute coronary syndrome. Journal of Clinical Hypertension, 2006 , 8:315-322.

13. Thune $\mathrm{J} \mathrm{J}$ et al. Effect of antecedent hypertension and follow-up blood pressure on outcomes after high-risk myocardial infarction. Hypertension, 2008, 51:48-54.

14. Willich SN et al. PIN Study Group. Cardiac risk factors, medication, and recurrent clinical events after acute coronary disease; a prospective cohort study. European Heart Journal, 2001, 22:307-313.

15. Piegas LS et al., AFIRMAR Study Investigators. Risk factors for myocardial infarction in Brazil. American Heart Journal, 2003, 146:331-338.

16. Al Suwaidi J et al., GUSTO-IIb, GUSTO-III, PURSUIT, Global Use of Strategies to Open Occluded Coronary Arteries. Platelet Glycoprotein IIb/IIla in Unstable Angina: Receptor Suppression Using Integrilin Therapy, PARAGON-A Investigators, Platelet IIb/IIla Antagonism for the Reduction of Acute coronary syndrome events in a Global Organization Network. Prognostic implications of abnormalities in renal function in patients with acute coronary syndromes. Circulation, 2002, 106:974-980.

17. Majahalme SK et al. Comparison of patients with acute coronary syndrome with and without systemic hypertension. American Journal of Cardiology, 2003, 92:258-263.
18. Boden WE. The post-myocardial infarction patient with hypertension. Long-term outcome. Postgraduate Medicine, 1992, 92:173-175, 179-180.

19. Ali I et al. Importance of a history of hypertension for the prognosis after acute myocardial infarction-for the Bucindolol Evaluation in Acute myocardial infarction Trial (BEAT) study group. Clinical Cardiology, 2004, 27:265-269.

20. Abrignani MG et al. In-hospital complications of acute myocardial infarction in hypertensive subjects. American Journal of Hypertension, 2005, 18:165-170.

21. Ivanuša $M$ et al. The influence of hypertension on in-hospital outcome in patients with acute myocardial infarction. Medicinski Glasnik, 2009, 6:53-59.

22. Al Suwaidi J et al. Prevalence of the metabolic syndrome in patients with acute coronary syndrome in six middle eastern countries. Journal of Clinical Hypertension, 2010, 12:890-899.

23. Aursnes I, Landmark K. More non-Q-wave myocardial infarctions but similar infarct sizes in patients with hypertension. Blood Pressure, 2000, 9:98-103.

24. Richards AM et al. Antecedent hypertension and heart failure after myocardial infarction. Journal of the American College of Cardiology, 2002, 39:1182-1188.

25. Bener A et al. The effect of hypertension as a predictor of risk for congestive heart failure patients over a 10-year period in a newly developed country. Blood Pressure, 2004, 13:41-46.

26. Alsheikh-Ali AA et al., Gulf RACE Investigators. Heart failure in patients hospitalized with acute coronary syndromes: observations from the Gulf Registry of Acute Coronary Events (Gulf RACE). European Journal of Heart Failure, 2009, 11:1135-1142.

27. Witt BJ et al. The incidence of stroke after myocardial infarction: a meta-analysis. American Journal of Medicine, 2006, 119(4):354.el-354.e9.

28. El-Menyar A et al. Comparison of men and women with acute coronary syndrome in six Middle Eastern countries. American Journal of Cardiology, 2009, 104:1018-1022.

29. Frazier CG et al., SYMPHONY and the Second SYMPHONY Investigators. Prevalence and management of hypertension in acute coronary syndrome patients varies by sex: observations from the Sibrafiban versus aspirin to Yield Maximum Protection from ischemic Heart events postacute cOroNary sYndromes (SYMPHONY) randomized clinical trials. American Heart Journal, 2005, 150:1260-1267. 